\title{
Subventricular zone progenitors in time and space: generating neuronal diversity
}

\section{Eduardo B. Sequerra *}

Instituto do Cérebro, Universidade Federal do Rio Grande do Norte, Natal, RN, Brazil

\section{Edited by:}

Caroline Rouaux, Institut National de la Santé et de la Recherche

Médicale (INSERM), France

Reviewed by:

Liliana Bernardino, University of Beira Interior, Portugal

Carlos Vicario-Abejón, Instituto

Cajal, Consejo Superior de

Investigaciones Científicas (CSIC),

Spain

Erica Butti, Ospedale San Raffaele,

Italy

\section{${ }^{*}$ Correspondence}

Eduardo B. Sequerra, Instituto do Cérebro, Universidade Federal do Rio Grande do Norte, Av.

Nascimento de Castro, 2155, Natal, 59056-450, RN, Brazil

e-mail: ebsequerra@gmail.com
The adult mammalian brain harbors a population of cells around their lateral ventricles capable of giving rise to new neurons throughout life. The so-called subventricular zone $(S V Z)$ is a heterogeneous germinative niche in regard to the neuronal types it generates. SVZ progenitors give rise to different olfactory bulb (OB) interneuron types in accordance to their position along the ventricles. Here, I review data showing the difference between progenitors located along different parts of the SVZ axes and ages. I also discuss possible mechanisms for the origin of this diversity.

Keywords: heterogeneity, interneuron sub-type, morphogens, transcription factors, cellular differentiation

\section{SVZ PROGENY IN SPACE AND TIME}

The SVZ is one of the main neural stem cell niches in the adult mammalian brain. SVZ progenitors continuously give rise to new neurons that migrate to and differentiate in the ipsilateral olfactory bulb (OB; Altman, 1969; Luskin, 1993; Lois and AlvarezBuylla, 1994). Once there, newly generated neurons differentiate into multiple neuronal types that participate in the $\mathrm{OB}$ local circuitry (Luskin, 1993; Brill et al., 2009; Merkle et al., 2014). Progenitors located at different positions of the antero-posterior and dorso-ventral axes of the lateral ventricles originate these neuronal types in a spatial-segregated manner (Figure 1; Merkle et al., 2007). However, it is still debated to which extent this co-relation between progenitor position and neuronal type generated is due to an internal program or distinct environmental factors impinging onto progenitors (for discussion see, Sequerra et al., 2013).

The first evidence supporting that the SVZ is indeed a heterogeneous territory came from a series of studies performed at Marla Luskin's lab. This group described that neuroblasts migrating to the OB proliferate (Menezes et al., 1995). However, many of them leave the cell cycle along the pathway forming a posterior to anterior gradient of proliferation along the RMS (Coskun and Luskin, 2001). The progenitors located along different points of dorso-ventral and antero-posterior axes of the ventricular wall display different cell cycle kinetics and cell type density (Falcão et al., 2012). Retroviral labeling of the proliferative progenitors in the anterior SVZ (Luskin, 1993) or at the horizontal limb of the rostral migratory stream (Smith and Luskin, 1998), demonstrated that progenitors of granular neurons leave the cell cycle earlier (more posteriorly) than the ones that will generate the periglomerular (PG) neurons. These data, later reproduced by other group (Hack et al., 2005), show that different populations of newly generated $\mathrm{OB}$ neurons segregate very early, while still migrating. But how early would such segregation take place?

During the embryonic development of the nervous system, different neuronal types are generated in morphogenetic territories that are formed through the establishment of gradients of diffusive molecules and the subsequent expression of typespecific transcription factors (TFs; Jessell, 2000). In the embryonic telencephalon, different types of neurons are generated according to their position in the dorso-ventral axis: cholinergic in the ventral ventricular zone (VZ), GABAergic in the ventrolateral and glutamatergic in the dorsal (Marín and Rubenstein, 2001). Therefore, a question to be addressed was whether the spatial segregation of the SVZ germinative niche could represent a continuum of that in the embryonic telencephalon. Since the adult neural stem cells of the SVZ are directly derived from radial glia cells (Alves et al., 2002; Tramontin et al., 2003; Merkle et al., 2004), it is possible to label their radial process at different pial locations during early postnatal stages and then track the progeny of the generated SVZ progenitors (Merkle et al., 2007; Ventura and Goldman, 2007). Surprisingly for that time, the dorsal radial glia, that during embryogenesis gives rise to glutamatergic cortical neurons (Schuurmans et al., 2004), was shown to contribute inhibitory $\mathrm{OB}$ interneurons after embryogenesis (Merkle et al., 2007; Ventura and Goldman, 2007), and the progeny of radial glia located at different positions of the lateral ventricle dorso-ventral and antero-posterior axes give rise to different OB interneuron subtypes (Figure 1; Kelsch et al., 2007; 
A

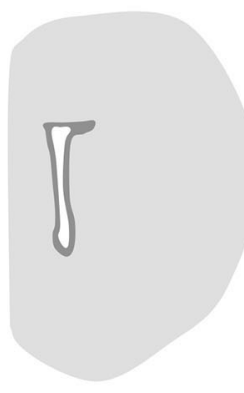

B

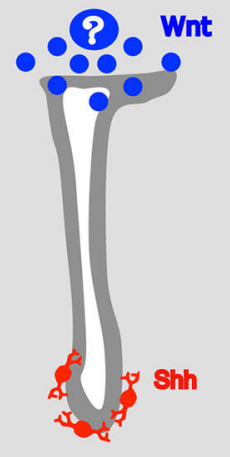

C

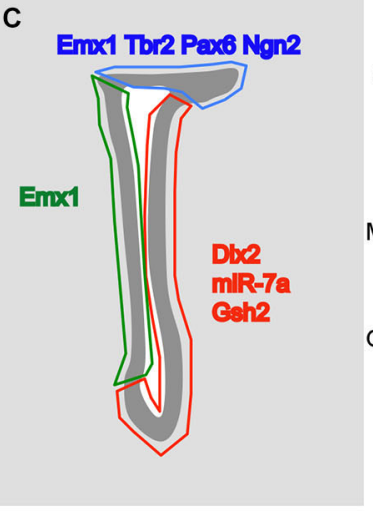

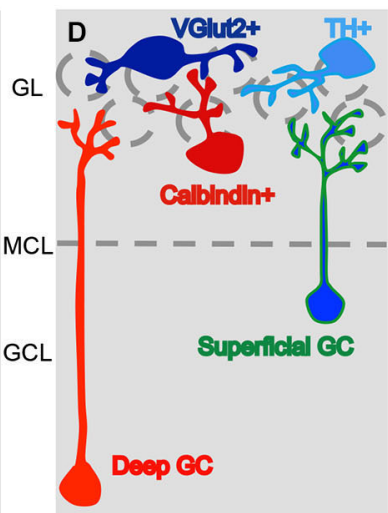

FIGURE 1 | A model for the origin of heterogeneity in the SVZ.

(A) Drawing of a coronal slice of one hemisphere, representing the lateral ventricle (in white) and the SVZ (in dark gray). (B) The morphogens so far described to influence the generation of different $O B$ interneuron subtypes. Wnt is produced dorsally, by an unknown source, and Shh is produced by neurons at the vicinity of the ventral SVZ. (C) These signaling molecules probably lead to differential expression of type-specific gene regulators dorsally (in blue) on the lateral wall, close to the striatum (in red) and on the medial wall, close to the septum (in green). (D) The expression of these regulators leads to the generation of OB interneuron type in a space-segregated manner. Neurons in blue are generated dorsally while the neurons in red come from ventral positions and the type in green and blue come both from the medial and dorsal SVZs. GCL-granular cell layer, MCL- mitral cell layer (represented by a dashed line), GL-glomerular layer (the glomeruli are represented by dashed circles).
Merkle et al., 2007; Paez-Gonzalez et al., 2014). Collectively, these data indicate that the adult ventricular wall is also divided in morphogenetic territories specialized in forming specific neuronal types.

Interestingly, different $\mathrm{OB}$ interneuron types are not only generated in a spatially segregated manner but also in a different time dynamics. De Marchis et al. (2007) injected Fluorogold in the anterior SVZ of neonatal and adult mice and described their progeny according to the neuronal types generated in the glomerular layer (GL). Batista-Brito et al. (2008) analyzed mice that had an inducible Cre-recombinase regulated by the Dlx1/2 enhancer, which is expressed in SVZ type C cells, in different time points, from embryogenesis to postnatal and adults. Li et al. (2011) analyzed the identity of new neurons labeled with BrdU at different ages. All three groups found that different OB interneuron types are generated in very specific time patterns, some exclusively during embryogenesis and first postnatal week, like the Parvalbumin ${ }^{+}$cells of the external plexiform layer (EPL; Batista-Brito et al., 2008; Li et al., 2011), but others keep their production consistently during life, like the granular and PG Calretinin $^{+}$cells (De Marchis et al., 2007; Batista-Brito et al., 2008; Li et al., 2011). Although most of the Tyrosine hydroylase $(\mathrm{TH})^{+}$PG neurons are generated embryonically and during the first postnatal week (Li et al., 2011), there are contradictory data in respect to the tendency of adult-generated neurons to give rise to this OB subtype. While Fluorogold (De Marchis et al., 2007) and BrdU injections (Whitman and Greer, 2007) suggest that a higher percentage of neurons born in the adult differentiate into $\mathrm{TH}^{+}$PG neurons, lineage analysis of the inducible Dlx1/2 enhancer progeny indicates that the percentage of cells that choose this type declines from embryogenesis to P30 (Batista-Brito et al., 2008). Independent of this contradiction, these data collectively show that the multiple types of $\mathrm{OB}$ subtypes are generated in a time-dependent fashion, suggesting dynamics in the activity of the SVZ during life. Since the different types are generated in different spatial domains it will be interesting to see if these domains are differentially regulated during time or if they can even fluctuate in size.

Different granular neuron subtypes are also mostly generated in segregated periods. The administration of BrdU or retroviral injections in the SVZ during the first postnatal week reveals that during this period superficial granular neurons are generated, whereas neurons generated in adults assume preferentially a deeper position (in respect to their position in the granular layer; Lemasson et al., 2005; Kelsch et al., 2007).

Although the main populations produced by the adult SVZ are granular or PG neurons (Luskin, 1993; Lois and Alvarez-Buylla, 1994), this region also produces other interneuron populations in a smaller number. The EPL has a much lower cell density than the granule cell layer (GCL) and GL. However, the EPL interneurons are generated at the SVZ with a peek during the first postnatal days but continuously along adulthood (Winner et al., 2002; Batista-Brito et al., 2008; Yang, 2008; Li et al., 2011). Merkle et al. (2014) recently described populations of EPL and mitral cell layer interneurons that are generated in the ventral SVZ during adulthood.

Through the analysis of the progeny of Neurog $2^{+}$progenitors, Brill et al. (2009) described the addition of a glutamatergic population to the PG population. PG neurons derived from these progenitors do not express Calretinin, TH, Sp8 or Calbindin and express the Vesicular glutamate transporter 2 (VGlut2; Brill et al., 2009). The morphologies of PG neurons from Neurog $2^{+}$lineage also vary over time. While neurons generated at embryonic stages project into the glomeruli, the posnatally-generated ones keep their dendrites around these structures (Winpenny et al., 2011). The adult-generated cells project to two or three glomeruli 
(Brill et al., 2009), a morphology typical of short-axon cells (Pinching and Powell, 1971). The neurochemical identity of short-axon neurons though, is currently under check. These cells were firstly described as glutamatergic since they do not have an active $\mathrm{GAD}_{65}$ promoter and the interglomerular transmission, attributed to these cells based on their morphology, is inhibited by ionotrophic glutamate receptors antagonists (Aungst et al., 2003). However, further histological (Kosaka and Kosaka, 2008; Kiyokage et al., 2010) and more careful functional analysis of their projection to the external tufted cells (Liu et al., 2013), show that interglomerular projecting neurons are actually GABAergic and dopaminergic instead of glutamatergic. The large soma $\mathrm{TH}^{+}$ cells in the GL, presumably short axon cells, are generated during embryogenesis and first postnatal week (Kosaka and Kosaka, 2009) and some of these neurons, co-expressing Parvalbumin at the border between the EPL and the GL, are generated in the postnatal but not the adult SVZ (Yang, 2008). Therefore, it remains unclear the role of the VGlut $2^{+}$, with short axon cell-like morphology, interneurons in the adult $\mathrm{OB}$ circuitry.

The segregation of the SVZ into multiple progenitor domains and windows leads us to ask what are the mechanisms involved in the generation of this diversity. For having some insights about this mostly unanswered question, I will review the existence of signaling pathways in the SVZ that can regulate the formation of domains for subtype-specific neurogenesis. I will also review the gene transcription regulators that have a regionally restricted pattern of expression and, therefore, can be downstream of these signaling pathways.

\section{ESTABLISHMENT OF MORPHOGENETIC TERRITORIES IN THE SVZ}

Being the SVZ a heterogeneous territory in respect to the neuronal populations it produces, how are these spatial differences formed? As said above, the embryonic ventricular cells are divided in morphogenetic territories and as the adult SVZ derives from it, the information can be passed on as an internal program. Alternatively, new information can be added in the postnatal/adult milieu either maintaining the original program or overwriting it.

The ventral adult SVZ display an active Sonic Hedgehog (Shh) signaling (Figure 1B; Ihrie et al., 2011). The disruption of this signaling in the ventral SVZ leads to a shift of production of $\mathrm{OB}$ interneurons to dorsal phenotypes, superficial granular cells and $\mathrm{TH}^{+} \mathrm{PG}$ neurons. The dorsal SVZ however, is irresponsive to Shh administration, unless a constitutively active Smo (a Shh receptor) is induced (Ihrie et al., 2011). Therefore, the adult morphogenetic environment constantly maintains the ventral SVZ territory. Although SVZ progenitors can respond to their environment, their receptor composition differs, and their plasticity is limited.

In opposition to ventral Shh, the dorsal SVZ displays Wnt signaling (Figure 1B; Azim et al., 2014). The activation of this signaling contributes to the activation of the dorsal TF Tbr2 (Azim et al., 2014). The knock down of the downstream players of Wnt/Planar cell polarity signaling, Dvl2 or Vangl2, leads to a specific decrease in the generation of superficial granular neurons (Hirota et al., 2012), that are typically generated in more dorsal parts of the SVZ (Figure 1D; Merkle et al., 2007). It is still not clear at what point interfering with Wnt signaling leads to the generation of ventrally-generated interneuron subtypes, however, it seems clear that dorsal TFs in the SVZ are positively affected by this molecule.

Therefore, the SVZ regionalization seems to be actively maintained during the adult life. Since the production of different interneuron subtypes is age-dependent it will be interesting to see how these signaling pathways fluctuate in time.

\section{THE SVZ MOLECULAR LANDSCAPE}

The differential expression of morphogens along the SVZ axes leads to the next step in cell line segregation that is an internal cascade of molecular events that lead to their specification into an $\mathrm{OB}$ neuronal subtype. TFs and microRNAs are expressed in discrete regions of the SVZ niche (Figure 1C).

Neurog2, Tbr2 and Tbr1, which are involved in specification of VGlut ${ }^{+}$interneurons of the GL, are restricted to the dorsal part of the SVZ around the lateral ventricles (Brill et al., 2009). Neurog 2 and Tbr2 are expressed by fast proliferating, type C cells while Tbr1 is expressed later in the lineage (Brill et al., 2009). Pax6, a TF that takes part both in $\mathrm{TH}^{+}$PG neuron (Hack et al., 2005; Kohwi et al., 2005; Brill et al., 2008) and in superficial granular neuron specification (Kohwi et al., 2005), is mostly expressed by the dorsal SVZ and by few cells in the lateral SVZ (Brill et al., 2008; de Chevigny et al., 2012a). The Emx1 lineage, that gives rise to superficial granule neurons and preferentially gives rise to Calretinin ${ }^{+}$interneurons, is restricted to the dorsal and septal SVZs (Kohwi et al., 2007; Young et al., 2007). Dlx2, which works in conjunction with Pax6 to specify dopaminergic PG neurons (Brill et al., 2008), is expressed mainly by cells of the lateral wall of the ventricle (where it has no clear role interneuron type specification) but the dorsally generated population turns it on after migrating as neuroblasts in the RMS (de Chevigny et al., 2012a). Pax6 restriction to the dorsal aspect of the SVZ is regulated by an opposing gradient of the micro-RNA miR-7a, inhibiting its translation. The inhibition of miR-7a expression leads to an increase in dopaminergic PG neuron production (de Chevigny et al., 2012b). The Gsh2 lineage is located at the lateral wall of the ventricle and seems to be the lineage that produces Calbindin ${ }^{+}$PG neurons (Young et al., 2007). Merkle et al. (2014) identified a subpopulation of SVZ cells located at the anterior region of the ventral lateral ventricles, that expresses Nkx6.2 and gives rise to EPL and mitral cell layer interneurons. Other TFs were shown to be restricted to a region of the SVZ, like Nkx2.1 and Dbxl (Young et al., 2007), but their contribution to the generation of the different subtypes is not available yet.

Therefore, the postnatal/adult SVZ seems to be compartmentalized. During development, the neuroepithelium gets divided in physical structures, called neuromeres, which differentially express adhesion molecules (Redies and Takeichi, 1996). Actually, EphB1, EphB2, ephrin-B and VCAM1 are expressed exclusively at the lateral wall of the SVZ (Conover et al., 2000; Kokovay et al., 2012) while EphB3 is expressed on the septal side (del Valle et al., 2011). It will be important in the future to test how the differential expression of these molecules restricts cellcell communication and migration and, consequently, the access of different populations to region-specific signaling molecules. 
Mellitzer et al. (1999) have shown that ephrin signaling restricts communication through GAP junctions to cells in the same neuromere. The postnatal dorsal SVZ (Freitas et al., 2012) and the adult lateral wall (Lacar et al., 2011) have local nets of astrocytes connected by GAP junctions but it is not clear at what extent these nets connect between compartments at the borders. A definite proof of the existence of physical compartments is still missing.

\section{RELEVANCE TO HUMAN ADULT SVZ PROGENITOR HETEROGENEITY}

Although the dynamics of $\mathrm{OB}$ interneuron subtype is very well described in mice, the relevance of this phenomenon for other species is starting to be understood. Of particular interest for medical sciences is the observation that in adult human OB there is little or no addition of new neurons (Sanai et al., 2011; Bergmann et al., 2012). However, for our discussion about the origin of the different $\mathrm{OB}$ interneuron subtypes, what is important is the source of these neurons. Is there a diversity of progenitors in the adult human brain capable of generating the $\mathrm{OB}$ interneuron pool? There is a massive reduction of neuroblast generation in the human lateral ventricles after the first year of life (Sanai et al., 2011) although the complete disappearance of neurogenesis in this region is controversial. There are groups that successfully detected neuronal markers, like PSANCAM, Dcx and and classIII-ßtubulin around the lateral ventricles (Curtis et al., 2007; Wang et al., 2011), on the olfactory tubercule (Wang et al., 2011) and around the olfactory ventricle (Curtis et al., 2007). Although these neuroblasts do not seem to be resulting in the addition of new neurons to the $\mathrm{OB}$, they are possibly a source for the recently documented addition of interneurons to the human adult striatum (Ernst et al., 2014). There is not a current molecular analysis of the heterogeneity of neuronal progenitors in the human SVZ although we can expect it to be a common feature in primates. This idea is supported by the demonstration that both macaques (Tonchev et al., 2006) and marmosets (Azim et al., 2013) express typespecific TFs in the SVZ. Marmosets have a specific reduction of $\mathrm{Tbr}^{+}$progenitors from first days of life to adulthood (Azim et al., 2013). Therefore, although the species differences have to be investigated, the theoretical piece of information collected in experimentation with rodents can still be relevant for the better understanding of the human SVZ heterogeneity of neuronal precursors.

\section{CONCLUSION}

The data published so far shows that the different neuronal lineages generated after birth to the $\mathrm{OB}$ are spatially and temporally segregated. Both morphogen signaling and molecular internal programs affect the specification of these cells.

Although we have some information on the internal programs of different interneuron subtypes and about their site and time of origin, little is known about how segregation between clones is kept. The criticisms lie around our technical limitations on testing the SVZ neural stem cells on their level of commitment. The argument supporting that clones in different locations are following an internal program is in dissonance with the observation that all the TFs cited above start to be expressed on type C cells or neuroblasts (for review, see Sequerra et al., 2013), not affecting the slow dividing stem cell on the top of the lineage. And the culture methods used so far for isolating stem cells, preferentially select fast dividing progenitors instead of the slow ones (for review, see Pastrana et al., 2011). Even the lack of response to Shh by dorsal progenitors detected by Ihrie et al. (2011) can be due to a lack of an inductive signal that makes these progenitors competent of responding to it (Waddington, 1940).

Although there are many similarities between the segregation of the embryonic and adult periventricular stem cell niches, there are important differences too. The adult brain is much bigger and less suitable for the establishment of molecular gradients. Instead, the adult SVZ has an intricate net of blood vessels (Mercier et al., 2002; Shen et al., 2008; Tavazoie et al., 2008; Snapyan et al., 2009) and axons (Höglinger et al., 2004, 2014; Paez-Gonzalez et al., 2014; Tong et al., 2014) bringing new players to the niche. Actually, the source of Shh to the ventral SVZ is composed of neurons located at the septum, preoptic nuclei and the stria terminalis, neurons that project into the SVZ (Figure 1B; Ihrie et al., 2011). The elimination of dopaminergic projections from the substantia nigra decreases proliferation in the SVZ (Baker et al., 2004) and it was recently shown that the substantia nigra and the ventral tegmented area project to distinct regions of the lateral ventricle wall (Höglinger et al., 2014). It is possible then, that activity in distinct brain regions differentially modulate SVZ progenitors depending on their location. Therefore, although some signaling pathways and molecular tools are re-used in the adult SVZ, the way they are played can be completely new, not seen in embryos.

There is clearly a lot to be done from now on. Many studies in the past considered the SVZ a homogeneous population. Molecules that were tested for general neurogenesis (for review, Lim and Alvarez-Buylla, 2014), for example, can be affecting a specific population and not others. New studies have to take into account the influence of signaling molecules to different SVZ populations, the differential expression of molecular determinants along the ventricle axes, and the consequences of changes in these dynamics to the generation of the different $\mathrm{OB}$ interneuron populations.

\section{REFERENCES}

Altman, J. (1969). Autoradiographic and histological studies of postnatal neurogenesis. IV. Cell proliferation and migration in the anterior forebrain, with special reference to persisting neurogenesis in the olfactory bulb. J. Comp. Neurol. 137, 433-457. doi: 10.1002/cne.901370404

Alves, J. A., Barone, P., Engelender, S., Fróes, M. M., and Menezes, J. R. (2002). Initial stages of radial glia astrocytic transformation in the early postnatal anterior subventricular zone. J. Neurobiol. 52, 251-265. doi: 10.1002/neu. 10087

Aungst, J. L., Heyward, P. M., Puche, A. C., Karnup, S. V., Hayar, A., Szabo, G., et al. (2003). Centre-surround inhibition among bulb glomeruli. Nature 426, 623-629. doi: 10.1038/nature02185

Azim, K., Fischer, B., Hurtado-Chong, A., Draganova, K., Cantù, C., Zemke, M., et al. (2014). Persistent Wnt/B-Catenin signaling determines dorsalization of the postnatal subventricular zone and neural stem cell specification into oligodendrocytes and glutamatergic neurons. Stem Cells 32, 1301-1312. doi: 10. 1002/stem.1639

Azim, K., Zweifel, S., Klaus, F., Yoshikawa, K., Amrein, I., and Raineteau, O. (2013). Early decline in progenitor diversity in the marmoset lateral ventricle. Cereb Cortex 23, 922-931. doi: 10.1093/cercor/bhs085 
Baker, S. A., Baker, K. A., and Hagg, T. (2004). Dopaminergic nigrostriatal projections regulate neural precursor proliferation in the adult mouse subventricular zone. Eur. J. Neurosci. 20, 575-579. doi: 10.1111/j.1460-9568.2004. 03486.x

Batista-Brito, R., Close, J., Machold, R., and Fishell, G. (2008). The distinct temporal origins of olfactory bulb interneuron subtypes. J. Neurosci. 28, 39663975. doi: 10.1523/jneurosci.5625-07.2008

Bergmann, O., Liebl, J., Bernard, S., Alkass, K., Yeung, M. S. Y., Steier, P., et al. (2012). The age of olfactory bulb interneurons in humans. Neuron 74, 634-639. doi: 10.1016/j.neuron.2012.03.030

Brill, M. S., Ninkovic, J., Winpenny, E., Hodge, R. D., Ozen, I., Yang, R., et al. (2009). Adult generation of glutamatergic olfactory bulb interneurons. Nat. Neurosci. 12, 1524-1533. doi: 10.1038/nn.2416

Brill, M. S., Snapyan, M., Wohlfrom, H., Ninkovic, J., Jawerka, M., Mastick, G. S., et al. (2008). A Dlx2- and Pax6-dependent transcriptional code for periglomerular neuron specification in the adult olfactory bulb. J. Neurosci. 28, 6439-6452. doi: 10.1523/jneurosci.0700-08.2008

Conover, J. C., Doetsch, F., Garcia-Verdugo, J., Gale, N. W., Yancopoulos, G. D., and Alvarez-Buylla, A. (2000). Disrutpion of Eph/ephrin signaling affects migration and proliferation in the adult subventricular zone. Nat. Neurosci. 3, 1091-1097. doi: $10.1038 / 80606$

Coskun, V., and Luskin, M. B. (2001). The expression pattern of the cell cycle inhibitor p19(INK4d) by progenitor cells of the rat embryonic telencephalon and neonatal anterior subventricular zone. J. Neurosci. 21, 3092-3103.

Curtis, M. A., Kam, M., Nannmark, U., Andreson, M. F., Axell, M. Z., Wikkelso, C., et al. (2007). Human neuroblasts migrate to the olfactory bulb via a lateral ventricular extension. Science 315, 1243-1249. doi: 10.1126/science.11 36281

de Chevigny, A., Coré, N., Follert, P., Gaudin, M., Barbry, P., Béclin, C., et al. (2012b). miR-7a regulation of Pax6 controls spatial origin of forebrain dopaminergic neurons. Nat. Neurosci. 15, 1120-1126. doi: 10.1038/nn.3142

de Chevigny, A., Core, N., Follert, P., Wild, S., Bosio, A., Yoshikawa, K., et al. (2012a). Dynamic expression of the pro-dopaminergic transcription factors Pax6 and Dlx2 during postnatal olfactory bulb neurogenesis. Front. Cell. Neurosci. 6:6. doi: 10.3389/fncel.2012.00006

De Marchis, S., Boveti, S., Carletti, B., Hsieh, Y., Garzotto, D., Peretto, P., et al. (2007). Generation of distinct types of periglomerular olfactory bulb interneurons during development and in adult mice: implication for intrinsic properties of the subventricular zone progenitor population. J. Neurosci. 27, 657-664. doi: 10.1523/jneurosci.2870-06.2007

del Valle, K., Theus, M. H., Bethea, J. R., Liebl, D. J., and Ricard, J. (2011). Neural progenitors proliferation is inhibited by EphB3 in the developing subventricular zone. Int. J. Dev. Neurosci. 29, 9-14. doi: 10.1016/j.ijdevneu.2010. 10.005

Ernst, A., Alkass, K., Bernard, S., Salehpour, M., Perl, S., Tisdale, J., et al. (2014). Neurogenesis in the striatum of the adult human brain. Cell 156, 1072-1083. doi: 10.1016/j.cell.2014.01.044

Falcão, A. M., Palha, J. A., Ferreira, A. C., Marques, F., Sousa, N., and Sousa, J. C. (2012). Topographical analysis of the subependymal zone neurogenic niche. PLoS One 7:e38647. doi: 10.1371/journal.pone.0038647

Freitas, A. S., Xavier, A. L. R., Furtado, C. M., Hedin-Pereira, C., Fróes, M. M., and Menezes, J. R. L. (2012). Dye coupling and connexin expression by cortical radial glia in the early postnatal subventricular zone. Dev. Neurobiol. 72, 14821497. doi: 10.1002/dneu.22005

Hack, M. A., Saghatelyan, A., de Chevigny, A., Pfeifer, A., Ashery-Padan, R., Lledo, P., et al. (2005). Neuronal fate determinants of adult olfactory bulb neurogenesis. Nat. Neurosci. 8, 865-872. doi: 10.1038/nn1479

Hirota, Y., Sawada, M., Kida, Y. S., Huang, S., Yamada, O., Sakagushi, M., et al. (2012). Roles of planar cell polarity signaling in maturation of neuronal precursor cells in the postnatal mouse olfactory bulb. Stem Cells 30, 1726-1733. doi: 10. 1002/stem.1137

Höglinger, G. U., Arias-Carrión, O., Ipach, B., and Oertel, W. H. (2014). Origin of the dopaminergic innervation of adult neurogenic areas. J. Comp. Neurol. 522, 2336-2348. doi: 10.1002/cne.23537

Höglinger, G. U., Rizk, P., Muriel, M. P., Duyckaerts, C., Oertel, W. H., Cailie, I., et al. (2004). Dopamine depletion impairs precursor cell proliferation in Parkinson disease. Nat. Neurosci. 7, 726-735. doi: 10.1038/nn1265

Ihrie, R. A., Shah, J. K., Harwell, C. C., Levine, J. H., Guinto, C. D., Lezameta, M., et al. (2011). Persistent sonic hedgehog signaling in adult brain determines neural stem cell positional identity. Neuron 71, 250-262. doi: 10.1016/j.neuron. 2011.05 .018

Jessell, T. M. (2000). Neuronal specification in the spinal cord: inductive signals and transcriptional codes. Nat. Rev. Genet. 1, 20-29. doi: 10.1038/35049541

Kelsch, W., Mosley, C. P., Lin, C. W., and Lois, C. (2007). Distinct mammalian precursors are commited to generate neurons with defined dendritic projection partterns. PLoS Biol. 5:e300. doi: 10.1371/journal.pbio.0050300

Kiyokage, E., Pan, Y., Shao, Z., Kobayashi, K., Szabo, G., Yanagawa, Y., et al. (2010). Molecular identity of periglomerular and short axon cells. J. Neurosci. 30, 11851196. doi: 10.1523/jneurosci.3497-09.2010

Kohwi, M., Osumi, N., Rubenstein, J. R., and Alvarez-Buylla, A. (2005). Pax6 is required for making specific subpopulations of granule and periglomerular neurons in the olfactory bulb. J. Neurosci. 25, 6997-7003. doi: 10.1523/jneurosci. 1435-05.2005

Kohwi, M., Petryniak, M. A., Long, J. E., Ekker, M., Obata, K., Yanagawa, Y., et al. (2007). A subpopulation of olfactory bulb GABAergic interneurons is derived from Emx1- and Dlx5/6-expressing progenitors. J. Neurosci. 27, 6878-6891. doi: 10.1523/jneurosci.0254-07.2007

Kokovay, E., Wang, Y., Kusek, G., Wurster, R., Lederman, P., Lowry, N., et al. (2012). VCAM1 is essential to maintain the structure of the SVZ niche and acts as an environmental sensor to regulate SVZ lineage progression. Cell Stem Cell 11, 220-230. doi: 10.1016/j.stem.2012.06.016

Kosaka, T., and Kosaka, K. (2008). Tyrosine hydroxylase-positive GABAergic juxtaglomerular neurons are the main source of the interglomerular connections in the mouse main olfactory bulb. Neurosci. Res. 60, 349-354. doi: 10.1016/j. neures.2007.11.012

Lacar, B., Young, S. Z., Platel, J., and Bordey, A. (2011). Gap junction-mediated calcium waves define communication networks among murine postnatal neural progenitor cells. Eur. J. Neurosci. 34, 1895-1905. doi: 10.1111/j.1460-9568.2011. 07901.x

Lemasson, M., Sahatelyan, A., Olivo-Marin, J., and Lledo, P. (2005). Neonatal and adult neurogenesis provide distinct populations of newborn neurons to the mouse olfactory bulb. J. Neurosci. 25, 6816-6825. doi: 10.1523/jneurosci.111405.2005

Li, X., Sun, C., Lin, C., Ma, T., Madhavan, M. C., Campbell, K., et al. (2011) The transcription factor $\mathrm{Sp} 8$ is required for the production of parvalbuminexpressing interneurons in the olfactory bulb. J. Neurosci. 31, 8450-8455. doi: 10.1523/jneurosci.0939-11.2011

Lim, D., and Alvarez-Buylla, A. (2014). Adult neural stem cells stake their ground. Trends Neurosci. 37, 563-571. doi: 10.1016/j.tins.2014.08.006

Liu, S., Planchez, C., Shao, Z., Puche, A., and Shipley, M. T. (2013). Olfactory bulb short axon cell release of GABA and dopamine produces a temporally biphasic inhibition-excitation response in external tufted cells. J. Neurosci. 33, 29162926. doi: 10.1523/jneurosci.3607-12.2013

Lois, C., and Alvarez-Buylla, A. (1994). Long-distance neuronal migration in the adult mammalian brain. Science 264, 1145-1148. doi: 10.1126/science.8178174

Luskin, M. B. (1993). Restricted proliferation and migration of postnatally generated neurons derived from the forebrain subventricular zone. Neuron 11, 173189. doi: 10.1016/0896-6273(93)90281-u

Marín, O., and Rubenstein, J. L. (2001). A long, remarkable journey: tangential migration in the telencephalon. Nat. Rev. Neurosci. 2, 780-790. doi: 10. $1038 / 35097509$

Mellitzer, G., Xu, Q., and Wilkinson, D. G. (1999). Eph receptors and ephrins restrict cell intermingling and communication. Nature 400, 77-81. doi: 10 $1038 / 21907$

Menezes, J. R. L., Smith, C. M., Nelson, K. C., and Luskin, M. B. (1995). The division of neuronal progenitor cells during migration in the neonatal mammalian forebrain. Mol. Cell. Neurosci. 6, 496-508. doi: 10.1006/mcne.19 95.0002

Mercier, F., Kitasako, J. T., and Hatton, G. I. (2002). Anatomy of the brain neurogenic zones revisited: fractones and the fibroblast/macrophage network. J. Comp. Neurol. 451, 170-188. doi: 10.1002/cne.10342

Merkle, F. T., Fuentealba, L. C., Sanders, T. A., Magno, L., Kessaris, N., and AlvarezBuylla, A. (2014). Adult neural stem cells in distinct microdomains generate previously unknown interneuron types. Nat. Neurosci. 17, 207-214. doi: 10. 1038/nn.3610

Merkle, F. T., Mirzadeh, Z., and Alvarez-Buylla, A. (2007). Mosaic organization of neural stem cells in the adult brain. Science 317, 381-384. doi: 10.1126/science. 1144914 
Merkle, F. T., Tramontin, A. D., García-Verdugo, J. M., and Alvarez-Buylla, A. (2004). Radial glia give rise to adult neural stem cells in the subventricular zone. Proc. Natl. Acad. Sci. U S A 101, 17528-17532. doi: 10.1073/pnas.04078 93101

Paez-Gonzalez, P., Asrican, B., Rodriguez, E., and Kuo, C. T. (2014). Identification of distinct $\mathrm{ChAT}^{+}$neurons and activity-dependent control of postnatal SVZ neurogenesis. Nat. Neurosci. 17, 934-942. doi: 10.1038/nn.3734

Pastrana, E., Silva-Vargas, V., and Doetsch, F. (2011). Eyes wide open: a critical review of sphere-formation as an assay for stem cells. Cell Stem Cell 8, 486-498. doi: 10.1016/j.stem.2011.04.007

Pinching, A. J., and Powell, T. P. S. (1971). The neuron types of the glomerular layer of the olfactory bulb. J. Cell Sci. 9, 305-345.

Redies, C., and Takeichi, M. (1996). Cadherins in the developing nervous system: an adhesive code for segmental and functional subdivisions. Dev. Biol. 180, 413423. doi: 10.1006/dbio.1996.0315

Sanai, N., Nguyen, T., Ihrie, R. A., Mirzadeh, Z., Tsai, H., Wong, M., et al. (2011). Corridors of migrating neurons in the human brain and their decline during infancy. Nature 478, 382-386. doi: 10.1038/nature10487

Schuurmans, C., Armant, O., Nieto, M., Stenman, J. M., Britz, O., Klenin, N., et al. (2004). Sequential phases of cortical specification involve Neurogeneindependent and -independent pathways. EMBO J. 23, 2892-2902. doi: 10. 1038/sj.emboj.7600278

Sequerra, E. B., Costa, M. R., Menezes, J. R. L., and Hedin-Pereira, C. (2013). Adult neural stem cells: plastic or restricted neuronal fates? Development 140, 33033309. doi: 10.1242/dev.093096

Shen, Q., Wang, Y., Kokovay, E., Lin, G., Chuang, S., Goderie, S. K., et al. (2008). Adult SVZ stem cells lie in a vascular niche: a quantitative analysis of niche cell-cell interactions. Cell Stem Cell 3, 289-300. doi: 10.1016/j.stem.2008. 07.026

Smith, C. M., and Luskin, M. B. (1998). Cell cycle length of olfactory bulb neuronal progenitors in the rostral migratory stream. Dev. Dyn. 213, 220-227. doi: 10. 1002/(sici)1097-0177(199810)213:2<220::aid-aja7>3.0.co;2-i

Snapyan, M., Lemasson, M., Brill, M. S., Blais, M., Massouh, M., Ninkovic, J., et al. (2009). Vasculature guides migrating neuronal precursors in the adult mammalian forbrain via brain-derived neurotrophic factor signaling. J. Neurosci. 29, 4172-4188. doi: 10.1523/jneurosci.495608.2009

Tavazoie, M., Van der Veken, L., Silva-Vargas, V., Louissaint, M., Colonna, L., Zaidi, B., et al. (2008). A specialized vascular niche for adult neural stem cells. Cell Stem Cell 3, 279-288. doi: 10.1016/j.stem.2008.07.025

Tonchev, A. B., Yamashima, T., Sawamoto, K., and Okano, H. (2006). Transcription factor protein expression patterns by neural or neuronal progenitor cells of adult monkey subventricular zone. Neurosci. 139, 1355-1367. doi: 10.1016/j. neuroscience.2006.01.053

Tong, C. K., Chen, J., Cebrián-Silla, A., Mizradeh, Z., Obernier, K., Guinto, C. D., et al. (2014). Axonal control of the adult neural stem cell niche. Cell Stem Cell 14, 500-511. doi: 10.1016/j.stem.2014.01.014
Tramontin, A. D., García-Verdugo, J. M., Lim, D. A., and Alvarez-Buylla, A. (2003) Postnatal development of radial glia and the ventricular zone (VZ): a continuum of the neural stem cell compartment. Cereb. Cortex 13, 580-587. doi: 10. 1093/cercor/13.6.580

Ventura, R. E., and Goldman, J. E. (2007). Dorsal radial glia generate olfactory bulb interneurons in the postnatal murine brain. J. Neurosci. 27, 4297-4302. doi: 10. 1523/jneurosci.0399-07.2007

Waddington, C. H. (1940). Organisers and Genes. Cambridge: Cambridge University Press.

Wang, C., Liu, F., Liu, Y., Zhao, C., You, Y., Wang, L., et al. (2011). Identification and characterization of neuroblasts in the subventricular zone and rostral migratory stream of the adult human brain. Cell Res. 21, 1534-1550. doi: 10.1038/cr. 2011.83

Whitman, M. C., and Greer, C. A. (2007). Adult-generated neurons exhibit diverse developmental fates. Dev. Neurobiol. 67, 1079-1093. doi: 10.1002/dneu.20389

Winner, B., Cooper-Khun, C. M., Aigner, R., Winkler, J., and Kuhn, H. G. (2002). Long-term survival and cell death of newly generated neurons in the adult rat olfactory bulb. Eur. J. Neurosci. 16, 1681-1689. doi: 10.1046/j.1460-9568.2002. 02238.x

Winpenny, E., Lebel-Potter, M., Fernandez, M. E., Brill, M. S., Götz, M., Guillemot, F., et al. (2011). Sequential generation of olfactory bulb glutamatergic neurons by Neurog2-expressing precursor cells. Neural Dev. 6:12. doi: 10.1186/17498104-6-12

Yang, Z. (2008). Postnatal subventricular zone progenitors give rise mot only to granular and periglomerular interneurons but also to interneurons in the external plexiform layer of the rat olfactory bulb. J. Comp. Neurol. 506, 347-358. doi: $10.1002 /$ cne.21557

Young, K. M., Fogarty, M., Kessaris, N., and Richardson, W. D. (2007). Subventricular zone stem cells are heterogeneous with respect to their embryonic origins and neurogenic fates in the adult olfactory bulb. J. Neurosci. 27, 8286-8296. doi: 10. 1523/jneurosci.0476-07.2007

Conflict of Interest Statement: The author declares that the research was conducted in the absence of any commercial or financial relationships that could be construed as a potential conflict of interest.

Received: 25 September 2014; accepted: 01 December 2014; published online: 22 December 2014.

Citation: Sequerra EB (2014) Subventricular zone progenitors in time and space: generating neuronal diversity. Front. Cell. Neurosci. 8:434. doi: 10.3389/fncel.2014.00434 This article was submitted to the journal Frontiers in Cellular Neuroscience.

Copyright (C) 2014 Sequerra. This is an open-access article distributed under the terms of the Creative Commons Attribution License (CC BY). The use, distribution and reproduction in other forums is permitted, provided the original author(s) or licensor are credited and that the original publication in this journal is cited, in accordance with accepted academic practice. No use, distribution or reproduction is permitted which does not comply with these terms. 